\title{
O PAPEL DAS VIVÊNCIAS NO AUFBAU
}

\author{
Sofia Inês Albornoz Stein*
}

RESUMO Este artigo faz a análise de alguns aspectos do sistema de constituição do Logische Aufbau der Welt (A construção lógica do mundo) de Rudolf Carnap, tendo em vista duas possíveis interpretações da base autopsicológica escolhida pelo autor, ou seja, das vivências. Alguns autores, como Michael Friedman e Moulines, vêem o Aufbau como sendo um sistema estrutural cujas formas não são determinadas pelas experiências básicas - pelas vivências. Outros, como, por exemplo, Stegmüller, afirmam que as estruturas, as definições do Aufbau, resultam de relações que podem ser estabelecidas entre estas. Acompanhando os argumentos desses intérpretes e a proposta epistemológica do próprio Carnap, sustento a necessidade de pensar a base autopsicológica, as vivências, como determinantes das relações estruturais do Aufbau.

Palavras-chave Rudolf Carnap, sistema de constituição, vivências, empirismo, estruturalismo

ABSTRACT This paper is an analysis of some aspects of the constitutional system of Carnap's Logische Aufbau der Welt. It considers two possible interpretations of the autopsychological basis - the elementary experiences - as this concept is used in Carnap's book. Some authors, like Michael Friedman and Moulines, see the Aufbau as a structural system whose forms are not determined by basic experiences - elementary experiences. Others, as for instance Stegmüller, say that the structures, the definitions, within

Professora Adjunta do Departamento de Filosofia da Universidade Federal de Pelotas. Artigo recebido em outubro de 2004 e aprovado em novembro de 2004. (siastein@mac.com)

KRITERION, Belo Horizonte, $n^{0}$ 110, Dez/2004, p. 224-237 
the Aufbau are the result of relations which can be established among those experiences. Following the arguments of these interpreters as well as Carnap's epistemological proposal, I sustain in this paper that it is necessary to think about the autopsychological basis - the elementary experiences - as determining Aufbau's structural relations.

Key-words Rudolf Carnap, constructional system, elementary experiences, empiricism, structuralism

A proposta fenomenalista do Aufbau é criticada de variados ângulos. Com relação à base empírica, os elementos primitivos, as vivências e as relações primitivas, as recordações de semelhança entre vivências, a crítica passa, por um lado, pela constatação da falta de correspondência factual da descrição carnapiana com o que acontece realmente — ou que poderia supostamente acontecer — na mente humana, e, por outro lado, pela acusação de "formalismo" da construção que Carnap faz tendo como ponto de partida as vivências.

Farei uma exposição desses dois aspectos da crítica à base do sistema de constituição do Aufbau com o objetivo principal de tentar esclarecer o real papel das vivências nesse sistema. Ou seja, com o objetivo de tentar localizar até que ponto o "conteúdo" das vivências é determinante da forma ou estrutura do sistema de constituição e até que ponto esta estrutura independe do conteúdo das vivências, de uma referência a vivências autopsicológicas.

\section{A corrente de vivências}

Além das influências que Carnap sofreu da fenomenologia e do positivismo atomista, o sistema do Aufbau apresenta traços idealistas — solipsistas e formalistas. O ponto de partida de Carnap no Aufbau são as vivências subjetivas de um sujeito, e estas vivências são "organizadas" formalmente com o auxílio da lógica moderna, da teoria dos tipos de Russell.

Em seu artigo "How Carnap built the world in 1928", Anders Wedberg, 40 anos após ter escrito "The logical construction of the world", de 1944, retoma a análise do processo de construção de conceitos efetuado por Carnap no Aufbau. Wedberg fixa a atenção na base do sistema, na corrente de vivências, assim como nas definições explícitas apresentadas por Carnap, tendo como relação primitiva a recordação de semelhança entre vivências. Segundo Wedberg:

[O] Aufbau é uma tentativa de explicar certos traços do mundo ou da realidade (o mundo, ou realidade, da ciência), ou do nosso conhecimento deste, por meio do estudo de 
um modelo. O modelo de mundo do Aufbau é "fenomenalista" ou mesmo "solipsista". Seus conceitos básicos pertencem à psicologia introspectiva e, particularmente, à fenomenologia da percepção. [...] O modelo de mundo do Aufbau é construído em acordo com o teoria simples dos tipos de Russell. Entre os seus elementos há, por conseguinte, certos "elementos básicos" (os indivíduos do Principia Mathematica) que formam a base para uma hierarquia de conjuntos e relações. Quando construimos um modelo de mundo estamos, segundo Carnap, livres para escolher os elementos básicos de muitas maneiras diferentes. No Aufbau ele os retira do reino "autopsicológico", isto é, da sua própria vida mental. (Wedberg, 1975, p. 17)

Para poder partir de forma mais ou menos consistente da base autopsicológica, Carnap tem de pressupor, como reitera no Prefácio à segunda edição do Aufbau, uma certa correspondência - de sensações e observações — entre as vidas psíquicas de diferentes sujeitos, o que, por si só, já é uma pressuposição bastante temerária. Os elementos básicos da vida autopsicológica são as experiências elementares, as vivências, que consistem na "totalidade de tudo aquilo que um sujeito experimenta num determinado momento do tempo" (Wedberg, 1975, p. 17), isto é, sensações, sentimentos e pensamentos. ${ }^{1}$ Como afirma Runggaldier, em seu livro Carnap's early convencionalism:

Carnap [...] tem de basear sua construção sobre um número finito de elementos básicos. Ele tem, portanto, de selecionar um certo subconjunto finito de teoricamente infinitos conjuntos de lugares. Mesmo que ele considere as experiências elementares como sendo aquilo que é primeiramente "dado", tanto psicologicamente quanto epistemologicamente, ele tem de tratá-las como abstrações de certo tipo, isto é, como meros lugares - finitos em número - na corrente. Entretanto, não é claro nem mesmo o que, no fundo, supõe-se que seja a corrente da experiência ela mesma. (Runggaldier, 1984, p. 82).

A relação ou conceito fundamental do sistema de constituição, a recordação de semelhança parcial entre vivências (Er), é uma relação diádica entre experiências de uma só pessoa (Wedberg, 1975, p. 19). Segundo Wedberg, essa noção de recordação de semelhança parcial entre vivências envolve pelo menos quatro fenômenos que devem ocorrer simultaneamente: (1) uma experiência elementar y; (2) a memória de uma experiência elementar anterior $\mathrm{x}$; (3) a comparação entre y e a imagem de x; (4) a descoberta de que x e y são parcialmente similares.

A escolha dessa relação como conceito primitivo do Aufbau, segundo Carnap afirma algumas vezes, deve-se não só à possibilidade lógica de utilização deste como ponto de partida do sistema, como conceito que permite definir

1 Não entrarei no mérito aqui de definir o que seriam "os momentos" para Carnap, ou seja, os cortes temporais aos quais seria submetida a corrente de vivências. 
outros conceitos - objetos - superiores na hierarquia, como também a que sua escolha permite uma reconstrução racional aproximada do processo real de construção de conceitos na vida mental. Essas duas intenções, de construção de um sistema axiomático consistente e de reconstrução do processo mental real de conceitos, não são tão fáceis de conjugar quanto Carnap faz parecer. Como repara Runggaldier: "Carnap faz afirmações diferentes em diferentes contextos no Aufbau. [...] Nas suas discussões preliminares, ele afirma diversas vezes que o sistema intenciona ser uma reconstrução racional da ordem epistêmica" (Runggaldier, 1984, p. 84), porém, no § 109, Carnap afirma que só é preciso postular as relações entre as experiências que são necessárias para construir a realidade a partir delas. Por isso, Runggaldier conclui que: "Este corresponde a um critério usado na escolha de axiomas para qualquer sistema formal, porque não é uma questão de se os axiomas são verdadeiros ou se são intuitivamente plausíveis, mas sim se os axiomas escolhidos funcionam como 'base' para o sistema” (Runggaldier, 1984, p. 84).

\section{O estruturalismo do Aufbau}

A noção de estrutura, utilizada por Russell para falar da relação entre números, é tomada de empréstimo por Carnap na construção de seu sistema de constituição. Segundo Kambartel, "[a]s descrições de estruturas dão a Carnap o instrumento lógico com cuja ajuda a concepção de um dado não interpretado conceitualmente e de sua elaboração conceitual lógica e temporalmente posterior deve se tornar possível". (Kambartel, 1976, p. 174). Conforme a interpretação de Kambartel, que pretendo questionar aqui, no Aufbau, o dado não carrega em si uma estrutura, ele seria a própria estrutura. Kambartel baseia-se nas próprias palavras de Carnap, que afirma: "[...] a ciência natural tem de distinguir entre tais complexos; isso ela faz no mais das vezes por meio de descrições com o auxílio de outros complexos, por último, entretanto, as descrições acontecem por meio de puras descrições estruturais". (Aufbau, § 12). A mera descrição da estrutura não permite, diz Kambartel, a identificação do objeto de forma tal a distingui-lo de outros objetos de mesma estrutura, que podem muito bem existir. Como a estrutura representa apenas um aspecto de um objeto, ou de uma composição de objetos, ela não consegue identificar e distinguir um objeto de outros de mesma estrutura. Por trás dessa crítica de Kambartel está a pressuposição de que objetos consistem em "algo mais" do que mera estrutura. Seria esse algo mais que os distinguiria entre si. Além desse algo mais não poder ser descrito por enunciados meramente estruturais, os enunciados teriam de conter descrições "qualitativas", que atribuem proprie- 
dades a objetos, e que, portanto, têm de ter um "sentido". Não podem consistir em descrições meramente estruturais, que descrevem estruturas, que fazem referência a relações estruturais. Carnap, assim também Kambartel, supõe que os elementos primitivos do sistema de constituição possam ser distinguidos por meio de descrições de estruturas, que são, elas próprias, descrições estruturais. Haveria, pois, segundo Kambartel, em Carnap, a suposição de que há um tipo de correspondência entre a estrutura lógico-formal da linguagem e a estrutura da realidade, que pode, em última análise, no sistema solipsista do Aufbau, ser interpretada como uma espécie de identidade: "o objeto é a sua estrutura", ele não apenas a apresenta.

Assim, afirma Kambartel, no Aufbau, "o empirismo de Carnap desemboca em uma fase formalista. A experiência imediata deve se tornar visível pela representação de uma base formal-estrutural. Ao critério do apelo à experiência liga-se o postulado da tradução de todos os conceitos e enunciados em conceitos e enunciados estruturalmente interpretados". (Kambartel, 1976, p. 181).

\section{Sobre o Fundamento do Conhecimento Empírico no Aufbau: as vi- vências}

O ponto de partida de Carnap no Aufbau — para efetuar a constituição dos conceitos ou objetos do conhecimento científico - é o "psíquico próprio", o subjetivo. Mesmo admitindo a possibilidade de outro ponto de partida, escolhe esse. Em que consiste o "psíquico próprio"? Victor Kraft, em seu comentário sobre o projeto do Aufbau, descreve a base do sistema de Carnap da seguinte maneira:

O que Carnap toma por base como vivencialmente dado não são elementos qualitativos discretos, elementos de sensação, como fazia o positivismo mais recente (Mach, Ziehen). Pois esses elementos são somente o resultado de uma abstração levada ao extremo, de uma reiterada construção conceitual. O que se vive são totalidades: percepções, pensamentos, sentimentos, tendências, disposições, enlaçados uns aos outros como um todo unitário, um "qual" específico em cada caso. O originário é a corrente contínua de vivências, que muda constantemente. As "vivências elementares" são unidades que não podem ser decompostas. (Kraft, 1966, p. 104)

Porém, apesar de ter como base as vivências - consideradas elementos unitários — o sistema de constituição do Aufbau — como sistema de definições explícitas de conceitos — não utiliza propriamente as vivências nas definições, mas o conceito não-definido, que representa uma relação de "recordação de semelhança" (Ähnlichkeitserinnerungen) entre partes de vivências, 
simbolizada por "Er". ${ }^{2}$ Os conceitos primitivos do Aufbau não são, portanto, exatamente conceitos de vivências, mas conceitos de "recordação de relações de semelhança entre (partes de) vivências". Todavia, pode-se questionar: como podem as vivências ser indecomponíveis e, ao mesmo tempo, serem estabelecidas relações entre "partes integrantes" dessas mesmas vivências? Essa decomposição não é, nos diz Carnap, "real", feita "de fato", mas fictícia, feita "por abstração", e é efetuada por "quase-análise". Conforme explica Kraft: "A 'quase-análise' consiste em estabelecer, para uma vivência elementar, relações de parentesco em virtude da recordação de semelhança, com o que se conserva indivisa a unidade da vivência. Deste modo, podem distinguir-se 'quase-elementos' na vivência elementar". (Kraft, 1966, p. 106).

Mais precisamente, pois, os conceitos primitivos do sistema de constituição do Aufbau são recordações de relações de semelhança entre partes integrantes de vivências, embora esses conceitos não sejam "epistemicamente" primitivos. Os elementos definidos a partir desses conceitos são "quaseelementos", aos quais se chega por "quase-análise". Assim, as sensações não são, como em Russell ou Mach, os elementos primitivos do Aufbau; elas são constituídas por abstração a partir das experiências fundamentais, das vivências, e definidas com o auxílio do conceito da relação de "recordação de semelhança" entre partes integrantes de vivências:

Portanto, a construção conceitual não parte aqui do mais específico, as sensações, como é corrente tanto na psicologia como em teoria do conhecimento, ascendendo delas até o que é cada vez mais geral, as qualidades como classes de sensações, destas aos campos sensoriais etc., mas inversamente: primeiro se constituem as classes mais gerais de quase-elementos e só delas se constróem as mais específicas: partindo das classes de qualidades, se constróem as classes de campos sensoriais, e só delas, as sensações. (Kraft, 1966, p. 108).

Carnap, no Aufbau, procura demonstrar concretamente que todos os conceitos empíricos da ciência são redutíveis a conceitos sobre a experiência. Para tanto, afirma que conceitos usados pela ciência empírica devem ser "redutíveis" a conceitos primitivos sobre a experiência. Mais precisamente, "um objeto (ou conceito) é dito 'redutível' a um ou mais objetos diferentes dele

2 No $\S 78$ do Aufbau, lemos: "A relação assimétrica nós queremos estabelecer como relação fundamental, nós a denominamos 'k recordação de semelhança k', e nós Ihe designamos o símbolo Er. ' $x$ Er y' ou 'k entre $x$ e y existe uma recordação de semelhança k' quer dizer, portanto: ' $p$ x e y são vivências elementares que, pela comparação de uma representação de recordação de x com y, são consideradas como parcialmente semelhantes p', o que nós podemos expressar resumidamente da seguinte forma: ' $p$ as vivências elementares x e y estão ligadas por recordação de semelhança p." As letras 'k' e 'p' no início e final das citações indicam que as citações estão escritas ou em linguagem do sistema de constituição (k) ou em linguagem da psicologia ( $p)$. 
quando todos os enunciados sobre ele se deixam transformar em enunciados sobre esses outros objetos". (Aufbau, § 2).

Tentativas interpretativas dos últimos anos aproximam o Aufbau de Carnap de um tipo de idealismo kantiano e negam, a partir dessa perspectiva, que nessa obra a ostensão, no sentido de mostrar ou apontar algo, mesmo que subjetivamente, tenha a mesma importância do que tinha para Russell, no Our Knowledge of External World (1914). Alan W. Richardson, que segue essa linha de interpretação, afirma o seguinte a respeito do sistema de constituição de Carnap:

[...] Carnap tem de providenciar o que ele chama uma "descrição definida estrutural" para um objeto se esse deve ser um objeto de conhecimento. Tal descrição definida estrutural destaca um objeto somente em virtude de suas relações lógicas a outros objetos da ciência. Se isso é possível, evita qualquer e todo apelo a uma relação de conhecimento ou ostensão privada, mas epistemicamente privilegiada. (Richardson, 1996, p. 312).

No entanto, se levarmos em conta essa interpretação, não fica claro qual é o fundamento ou a 'origem' (em sentido lógico) das relações estruturais entre os objetos ou conceitos do conhecimento empírico.

Em aparente oposição a Richardson, Stegmüller explica a tentativa carnapiana de constituição dos conceitos empíricos da ciência, que resulta em um sistema de definiçõoes estruturais, como só fazendo sentido de um ponto de vista empirista. Segundo Stegmüller, os conceitos, ligados por relações estruturais, só têm significado se for considerada a referência ao 'vivenciado' (à experiência):

O que pretendo dizer, ao usar uma palavra, não se pode tornar compreensível, salvo indicando uma característica empírica para os objetos abrangidos pelo conceito designado por essa palavra. Essa indicação deve ocorrer, no caso de expressões fundamentais não-definidas, por via direta, ou seja, pelo ato vivencial de mostrar algo. Já as expressões definidas têm suas características indicadas por meio de definições. Indiretamente, porém, aquilo que pode ser mostrado vivencialmente constitui a fonte última de significação. Pois a definição remete a conceitos fundamentais não definidos. (Stegmüller, 1977, p. 97).

Parece-me que, mesmo sendo possível identificar muitos traços "idealistas transcendentais" no Aufbau, a visão fundamental de que, em última instância, a estrutura conceitual se forma a partir daquilo que se apresenta na experiência e não anteriormente a ela, a não ser em seus aspectos lógicos e matemáticos, demonstra a inserção de Carnap na tradição empirista. O próprio Carnap afirma: 
Dado que, pela teoria da constituição, cada enunciado da ciência no fundo é um enunciado sobre as relações existentes entre as vivências elementares, todo conhecimento com conteúdo (isto é, não puramente formal) se reduz à experiência. Por isso é mais apropriada a designação "empirismo". (Aufbau, § 183)

\section{O tratamento da tese da extensionalidade no Aufbau}

Uma das teses centrais do Aufbau é a chamada tese da extensionalidade. A afirmação de que todo o conhecimento empírico advém de nossas vivências está associada à tese de que qualquer enunciado significativo acerca da experiência deve descrever um determinado conjunto de vivências ou conjunto de elementos dessas vivências. Ou seja, a visão de que a experiência é a fonte de todo significado e, por isso, também, o tribunal de tudo aquilo que é afirmado com significado apresenta-se conjugada, no Aufbau, à tese lógico-semântica que afirma serem todos os enunciados de uma linguagem significativa extensionais.

Esse enfoque empirista do conhecimento de Carnap não pretende cair no empirismo clássico, em que se afirma que as sensações produzem no sujeito certas idéias que passam a ser compreendidas, então, como "significados" mentais de palavras que as representam. Pelo contrário, o empirismo do Aufbau se pretende antipsicologista, antimentalista. Conteúdos empíricos, segundo Carnap, não são armazenados de maneira a formar "significados" mentais; conteúdos empíricos são sempre a "extensão" à qual as palavras se referem.

Em vez de analisar "palavras", Carnap parte da análise de "funções sentenciais" (Aussagefunktionen). Existem expressões lingüísticas, com determinada extensão, que são chamadas de predicados, e estes podem ser representados por funções sentenciais: "Cada função sentencial representa, portanto, um conceito, isto é, ou um atributo ou uma relação" (Aufbau, § 28). Uma função sentencial é satisfeita por determinados argumentos, ou seja, por nomes de objetos que formam a "extensão" do predicado. Carnap segue, pois, a formalização idealizada por Frege (1891). ${ }^{3}$ Entretanto, Carnap não utiliza, no Aufbau, para fins de análise de enunciados ou funções sentenciais — a não ser para mostrar que não lhe interessa falar do sentido destes - , a distinção fregeana entre sentido e significado (Sinn und Bedeutung). ${ }^{4}$

3 Sobre a função sentencial, diz Frege em "Função e Conceito" (1891): "A segunda parte é insaturada, ela contém um lugar vazio, e somente quando este lugar é preenchido através de um nome próprio, ou de uma expressão que represente um nome próprio, aparece o sentido completo" (Frege, 1978, p. 46).

4 As traduções inglesas dos termos "Sinn" e "Bedeutung" acabaram estabelecendo o termo "meaning" como tradução de "Sinn" e do termo "reference"' como tradução de "Bedeutung", apesar de as traduções literais serem "sense" e "meaning", respectivamente. 
Segundo Carnap, podemos traduzir qualquer enunciado para uma linguagem meramente extensional, utilizando exclusivamente símbolos que designam extensões. No caso da função sentencial, duas funções que são satisfeitas pelos mesmos argumentos podem ser simbolizadas pelo mesmo símbolo, não se diferenciam segundo o critério extensional: "Funções sentenciais de mesma abrangência são satisfeitas, portanto, por exatamente os mesmos argumentos". (Aufbau, § 31).

Extensões são "quase-objetos", não são objetos genuínos, são objetos construídos por "quase-análise", dentro do sistema de constituição do Aufbau. Extensões podem ser classes (atributos) ou relações (também espécies de classes). Classes e relações são extensões de funções sentenciais. Segundo a tese fundamental da teoria da constituição de Carnap, todos os objetos das ciências empíricas podem ser constituídos a partir dos mesmos objetos fundamentais apenas com o uso das classes e das relações, que são denominadas por Carnap "formas de progressão" (Stufenformen) (cf. Aufbau, § 42).

As definições elaboradas no interior do sistema de constituição do Aufbau podem simplesmente introduzir novos símbolos ou também mostrar a equivalência extensional entre duas funções sentenciais. Nesse segundo caso, as definições são chamadas de "definições de uso" (Gebrauchsdefinitionen). Afirmar a identidade lógica das extensões de duas funções sentenciais equivale a afirmar que a função sentencial em definição pode ser representada por determinados símbolos de extensão, isto é, por símbolos representando sua extensão. E é isso exatamente o que afirma a "tese da extensionalidade" (Extensionalitätsthese): "em cada enunciado sobre um conceito, esse conceito pode ser tomado extensionalmente, isto é, ser representado pela sua extensão (classe ou relação); mais precisamente: em cada enunciado sobre uma função sentencial, essa função pode ser substituída pelo seu símbolo de extensão" (Aufbau, § 43).

Segundo Carnap, quando afirmamos uma função sentencial, estamos querendo falar de sua extensão e não de sua intensão, pois para falar de sua intensão temos de mostrar que não estamos usando de forma comum a função; estamos querendo exprimir algo "outro" do significado normal da função, estamos querendo exprimir uma representação ou pensamento.

Um enunciado é definido por Carnap como "extensional" quando pode ser transformado em um enunciado sobre extensões (Extensionsaussage). Um enunciado sobre extensões pode ser tanto sobre classes quanto sobre relações. Unificando a análise das extensões de funções sentenciais à dos enunciados intensionais, Carnap formula novamente a tese da extensionalidade: 
Condição necessária e suficiente para que um enunciado sobre uma função sentencial f seja extensional é a de que, no enunciado, sem alteração de seu valor de verdade, possa ser colocada, no lugar de $\mathrm{f}$, qualquer outra função sentencial que tenha a mesma abrangência de $\mathrm{f}$. A tese da extensionalidade afirma que todos os enunciados sobre qualquer função sentencial são extensionais, e, portanto, não existem enunciados intensionais. (Aufbau, § 43).

Assim, a tese da extensionalidade afirma, segundo Carnap, que não existem enunciados intensionais sobre funções sentenciais, já que, se qualquer enunciado sobre uma função sentencial preserva o seu valor de verdade — caso a função da qual fale for substituída por uma função de mesma extensão —, então podemos representar extensionalmente toda função sentencial. Ainda, segundo Carnap, só a tradução extensional de uma função sentencial realmente representa a função, pois aquilo que entendemos pelo sentido ou intensão de uma função é um objeto distinto daquele que é significado pela própria função, ou seja, se dizemos que "[x é um homem] implica em geral: x é mortal", estamos falando da extensão da função sentencial "x é um homem", e não do seu sentido ou intensão. Falar do sentido seria falar de objetos de uma representação ou de um pensamento, cuja emergência é suscitada pela função. Enunciados intensionais seriam aqueles que fariam referência a representações e pensamentos que palavras suscitam e não a objetos significados pelas palavras. Porém, segundo minha interpretação, quando usamos normalmente enunciados, a pretensão é fazer referência a objetos e não a representações desses objetos. Aparentemente é isso que Carnap quer dizer quando afirma não existirem enunciados intensionais.

A tese da extensionalidade, segundo Carnap, vale tanto para enunciados sobre funções sentenciais quanto para enunciados sobre enunciados ou enunciados sobre objetos propriamente ditos. Dessa maneira, pode-se dizer que não existem enunciados intensionais; todos os enunciados são extensionais. Enunciados, funções sentenciais ou nomes podem ser substituídos por símbolos que tenham a mesma extensão, ou, na terminologia fregeana, o mesmo significado (Bedeutung), não importando que tenham sentidos diversos.

No $\S 50$ do Aufbau, Carnap distingue o valor lógico e o valor epistemológico de expressões lingüísticas. Essa distinção é um corolário da distinção fregeana entre sentido e significado. Logo, Carnap não elimina simplesmente a distinção de Frege, ele continua supondo a distinção, apesar de construir, no Aufbau, um sistema só de enunciados extensionais, cujo significado está determinado. E isso é o mesmo, segundo Carnap, que pressupor, na construção do seu sistema, apenas o "valor lógico" dos enunciados. As definições explícitas usadas no sistema de constituição preservam apenas o valor lógico de expressões ou enunciados. Diz-nos Carnap: 
Se uma sentença sobre um objeto é de tal forma transformada que, no lugar do nome do objeto, seja colocada a sua definição constitucional, então se altera, em alguns casos, o sentido de representação da sentença e, com isso, o seu valor para o conhecimento. [...] Na transformação constitucional de um enunciado (ou função sentencial), o valor lógico permanece sempre inalterado, mas não sempre o valor epistemológico. (Portanto, é uma tradução na qual, diversamente das traduções costumeiras, o conteúdo representacional não precisa permanecer o mesmo.) Nisso consiste uma característica essencial do método constitucional: ele leva em conta, em descrições de objetos, enunciados e funções sentenciais, somente o valor lógico, não o valor epistemológico; ele é puramente lógico, não psicológico. (Aufbau, § 50)

Mesmo seguindo, como afirmei anteriormente, em seu sistema de constituição, a ordem "epistemológica" dos objetos, isto é, a ordem pela qual os objetos são conhecidos, Carnap não pretende resgatar, nas definições explícitas de seu sistema, o "valor epistemológico" das expressões que designam objetos. Pode ser que esse valor seja preservado nas definições, mas não é essa uma finalidade do sistema.

Para entender o que Carnap quer dizer com "valor epistemológico", vale citar sua afirmação a respeito da ordem epistemológica entre objetos:

Um objeto (eventualmente uma espécie de objeto) é dito "epistemologicamente primário" em relação a outro, o "epistemologicamente secundário", quando o outro é, através da mediação do primeiro, identificado e, por isso, pressupõe, para a sua identificação, a identificação do primeiro. [...]

A consideração da relação epistemológica dos objetos não significa que as sínteses ou formações do conhecimento devam ser apresentadas em sua natureza concreta, tal como elas se apresentam no processo real de conhecimento, no sistema de constituição. Essas formações são reproduzidas no sistema de constituição só de maneira racionalizadora ou esquematizante; o conhecimento intuitivo é substituído por inferências discursivas. (Aufbau, § 54).

Da mesma maneira que a identificação de um objeto depende da identificação de outros objetos mais "primários" na ordem epistêmica, a compreensão do sentido de uma expressão pode depender da compreensão de uma determinada ordem epistêmica de objetos. Conforme, portanto, o sentido de uma expressão, pode mudar aquilo que se representa para alcançar a compreensão de qual ou quais objetos estão sendo referidos ou significados pela expressão.

Porém, Carnap — apesar de continuar utilizando a terminologia fregeana que faz a distinção entre o sentido (Sinn) e o significado (Bedeutung) de um símbolo lingüístico - defende unilateralmente que apenas o significado representa o objetivamente comunicável pelo símbolo. Todavia, essa conclusão de Carnap - que afirma serem extensionais todos os enunciados e não haver enunciados intensionais — não exclui, segundo me parece, os objetos 
intensionais, os sentidos de expressões ou enunciados, do mundo construído no Aufbau. Os objetos que seriam indicados pelos "pretensos" enunciados intensionais são o conteúdo de representações ou pensamentos, os quais são, por sua vez, objetos psíquicos. Os objetos psíquicos (próprios ou alheios) são constituídos no Aufbau, portanto podem ser definidos extensionalmente. Desse modo, os objetos "intensionais" — objetos significados em enunciados chamados de "intensionais" —, representações ou pensamentos, poderiam, em princípio, no sistema de constituição, ser reduzidos a extensões também. Acontece que, nesse caso, enunciados intensionais não seriam mais do que enunciados extensionais cujos objetos são representações. Cria-se, como se pode perceber, uma circularidade: todos os enunciados são extensionais, fazem referência a objetos, porém também suscitam a emergência de representações (sentidos). Para falar desses sentidos seriam necessários outros enunciados extensionais, cujos objetos seriam essas representações.

\section{A questão da referência à experiência no estruturalismo extensiona- lista do Aufbau}

O que Kambartel parece ignorar é que a descrição estrutural pretende "fazer referência" não meramente a um objeto estrutural, mas a um objeto ou objetos com determinadas qualidades, qualidades essas "experimentadas" vivenciadas - pelo sujeito.

Assim como a relação fundamental Er não é definida no sistema constitucional do Aufbau, mas simplesmente descrita em uma linguagem realista, também outros conceitos que vão sendo construídos são inicialmente descritos em linguagem realista mais intuitiva. Com relação à Er (recordação de semelhança entre vivências), Runggaldier comenta que ocorre uma circularidade argumentativa em sua descrição, "pois os elementos primitivos —vivências - são definidos com base em Er — como domínio da relação Er — e Er é introduzida — em linguagem realista — como relação que existe entre precisamente os mesmos elementos" (Runggaldier, p. 84).

Outra noção fenomenalista pré-sistemática do Aufbau é a noção de "esfera de qualidade". Essa noção tem o seu correlato no sistema de constituição na definição explícita d3 de "círculo de similaridade" da cadeia de definições apresentadas por Carnap (a primeira é a definição de "vivência", e a segunda, a de "similaridade parcial"). Todas as definições são efetuadas com base na relação primitiva de recordação de semelhança entre vivências. A questão que levanto é a seguinte: a definição estrutural ou formal d3 depende, para sua verdade, ou para a verdade de suas instâncias, da suposição da referência a 
algo empírico, não meramente estrutural? Segundo a interpretação de Kambartel esse não seria o caso.

Tomemos o exemplo descrito por Wedberg da esfera de qualidade do campo visual:

Um campo visual que é parte de minha atual experiência elementar é considerado no Aufbau como uma configuração espacial bidimensional de pontos coloridos. Cada ponto colorido é caracterizado por seus dois "sinais de localização", que juntos determinam o seu lugar no campo visual, e por seu matiz, saturação e brilho, que juntos determinam o seu lugar no sólido colorido. Nesse sentido, os pontos coloridos que ocorrem em uma experiência elementar podem ser pensados como pontos em um espaço penta-dimensional (a palavra "espaço" aqui entendida em um sentido abstrato), que pode ser chamado de espaço colorido. Os pontos coloridos que ocorrem em uma experiência elementar serão então um determinado subconjunto de um espaço colorido. [...] Se dois pontos p e p' são similares e se p ocorre em uma experiência elementar "e" e p' em "e", então "e" e "e"" são ditos serem parcialmente similares (teilähnlich). (Wedberg, 1975, p. 19).

\section{Segue Wedberg:}

Pontos coloridos são espécies do gênero pontos de qualidade. Em um nível de pensamento, em um sentido, Carnap considera uma experiência elementar como um complexo de um número de qualidade de diversos tipos. Um tipo são pontos visuais coloridos, outro são qualidades auditivas, um terceiro olfativo etc. Ele está também preparado a reconhecer qualidades emotivas, volitivas e intelectuais (pontos de qualidades). A palavra "classe sensorial" é usada para denotar tal tipo de qualidade. (Wedberg, 1975, p. 19).

A partir dessa descrição de Wedberg, a questão que propus inicialmente pode ser reformulada: em que medida se pode dizer que a determinação e a descrição de "círculos de similaridade" (esferas de qualidades), com vistas à formulação de enunciados estruturais, independe de algo anterior vivenciado? E até que ponto é necessário afirmar, para manter a consistência, que as estruturas formais dos enunciados do sistema de constituição dependem de certas características abstraídas de experiências elementares, que, elas próprias, não se reduzem a estruturas, mas podem ser, de alguma maneira "referidas", enquanto extensões, por meio dessas estruturas?

Segundo compreendo, não é possível ignorar o papel de características inerentes às experiências elementares — as vivências — que possibilitam a elaboração de enunciados estruturais - extensionais ou formais, que são, por assim dizer "o conteúdo", a referência, desses enunciados. Sem a suposição de um conteúdo empírico ao qual se faz referência por meio de enunciados estruturais, fica impossível pensar - e aqui podemos seguir a própria linha de raciocínio de Kambartel, só que para chegar a uma conclusão diferente - 
como se poderia distinguir entre esferas de qualidades, ou entre pontos coloridos, ou entre sensações olfativas. A distinção por meio de enunciados estruturais entre esses objetos só pode ocorrer devido à distinção prévia que é passível de ser feita, por quase-análise, entre certas características inerentes às vivências, que não são meramente estruturais.

\section{Referências}

CARNAP, Rudolf. Der Logische Aufbau der Welt. Hamburg: Felix Meiner Verlag, 1961. (Primeira edição: 1928).

FREGE, Gottlob. Sobre o conceito e o objeto. In: FREGE, G. Lógica e Filosofia da Linguagem. Trad. Paulo Alcoforado. São Paulo: Cultrix, 1978. . Sobre o sentido e a referência. In: Lógica e Filosofia da

Linguagem.Trad. Paulo Alcoforado. São Paulo: Cultrix, 1978.

FRIEDMAN, Michael. Carnap's Aufbau. Reconsidered. Nous, v. 21, p. 521-545, 1987. . Epistemology in the Aufbau. Synthese, v. 93, p. 15-57, 1992.

GOODMAN, Nelson. The significance of Der Logische Aufbau der Welt. In: SCHILPP, P. A. The philosophy of Rudolf Carnap. La Salle, Illinois/London: Open Court/ Cambridge University Press, 1963.

KAMBARTEL, Friedrich. Erfahrung und Struktur: Bausteine zu einer Kritik des Empirismus und Formalismus. Frankfurt am Main: Suhrkamp Verlag, 1976.

KRAFT, Victor. El Círculo de Viena. Madrid: Taurus Ediciones, 1986. (Primeira edição: 1966).

MOULINES, C. U. Hintergründe der Erkenntnistheorie des frühen Carnap. Grazer Philosophische Studien, v. 23, p. 1-18, 1984.

RICHARDSON, Alan W. From epistemology to the logic of science: Carnap's philosophy of empirical knowledge in the 1930s. Minnesota Studies in the Philosophy of Science, v. XVI, p. 309-334, 1996.

RUNGGALDIER, Edmund. Carnap's Early Convencionalism: an inquiry into the historical background of the Vienna Circle. Amsterdam: Editions Rodopi, 1984.

RUSSELL, Bertrand. Our Knowledge of External World. London: George Allen/Unwin Ltd., 1969. (Primeira edição: 1914).

STEGMÜLLER, Wolfgang. A filosofia contemporânea: introdução crítica. São Paulo: E.P.U./EDUSP, 1977. v.1.

WEDBERG, Anders. The logical construction of the world. Theoria, v. X, p. 216-246, 1944.

. How Carnap build the world in 1928. In: Rudolf Carnap,

logical empiricist: materials and perpectives. Dordrecht/Holland: Reidel Publishing Company, 1975. 